español entero es tan universal como peculiar. Exempla terrent: no queremos dejarnos abrumar por alegorías deshumanizadas, de pueblos encerrados en su determinación histórica, sin relación con lo universal, por un nuevo Dauerspanier moldeado sobre el Dauerfranzose de Eduard Wechssler ${ }^{10}$. El libro monumental de Castro, brillante acto de fe en los valores hispánicos particulares, visión monumental, de lo español por un gran ensayista español, paso decisivo él mismo en la ideología hispánica, debe ser sometido a la llamada "crítica fría" de la ciencia, que puede también brotar de una ardiente pasión: la pasión por la verdad.

Johns Hopkins University.

Leo Spitzer

\title{
RESPUESTA A LEO SPITZER
}

Es muy de agradecer que Spitzer se haya tomado la molestia de senalar algunas inexactitudes de detalle en mi España en su historia, y que incluso intente poner al descubierto los cimientos de mi obra. $\mathrm{Al}$ contestarle en el mismo amigable tono que él emplea, no lo haré con espíritu de polémica, sino para repensar algo más mis propios problemas.

Ya se sabe en cuánto descuido y omisión de detalle cae el autor de un extenso volumen mientras piensa en el conjunto de su obra, sin atenerse a cauces preexistentes. Yo no he pretendido probar ninguna tesis, ni hacer ver la acción de estas o las otras "influencias". He aspirado a hacer perceptible la realidad de una vida histórica, lo que puede hacérnosla captable y "nombrable" prescindiendo de generalidades que la disuelven en irrealidad abstracta, o en anécdotas caóticas. La historia es

10 Estamos peligrosamente cerca de un Dauerspanier cuando leemos (pág. 433) que si los monárquicos españoles escriben Rey con mayúscula y los republicanos con minúscula, es lo mismo que cuando "el Arcipreste quiere que entendamos su libro puntándolo según el aire de nuestra total existencia. Las letras se tañen como instrumentos y se modula su expresión en tono mayúsculo o minúsculo según el humor y el afecto de cada uno". Pero cuando la Action française escribe roy y los republicanos franceses roi, ¿también los franceses tañerán letras como instrumentos? - "La literatura española, como ninguna otra de Europa [el subrayado es mío], practicó el arte de convertir ciertos personajes literarios en figuras vivientes: Trotaconventos, Celestina, Lazarillo, don Quijote, Dulcinea, don Juan" (pág. 454); basta consultar el libro de Migliorini, Dal nome proprio al nome comune, con sus centenares de ejemplos sacados de las lenguas modernas (casos como el fr. amphitryon, pipelet, gavroche), para convencerse de que el paso del nombre propio (de origen literario o no) a nombre común no es nada privativo del español. "La toponimia hispanoamericana es una excelente revelación del integralismo hispánico, pues lo nombrado se incluye en la situación vital del nombrante" (Santo Domingo, así llamado por tres razones personales del fundador Bartolomé Colón; Cartagena, porque "este puerto es tan bueno como Cartagena"); en contraste Nueva York, que recuerda meramente otra ciudad del mismo nombre (pág. 667). Esta sutileza. se desvanece inmediatamente si pensamos en la significación de new en la toponimia de la América del Norte: 'regenerado'. Era una regeneración político-socialreligiosa, era un nuevo Canaán lo que esperaban los colonos, perseguidos en Inglaterra. ¿No es esto un integralismo anglo-sajón mediante el cual lo nombrado se incluye en la situación vital del nombrante? De todas maneras, España habría aparecido menos "peculiar" si Castro hubiera tenido en cuenta a la otra nación creyente, también geográficamente tangencial a Europa: la Rusia presoviética. 
vida revivida en vida, y no hay modo de salir de ahí. ¿'Tautología, irracionalismo? Lo importante para mí es que son ya muchos quienes me han honrado al manifestar que sienten su vida hispana bien refle jada en el espejo de mi libro. Para sentirme en él, en compañía de quienes hacen un problema de su existir hispánico - dichoso o desventurado, qué importa-, fueron escritas mis páginas, y no para añadir un número más a la mole ingente, y cada vez con menos sentido, de la informe e inabarcable sabiduría, la del saber para saber más. La verdad sin un "desde", un "como" y un "hacia", ya no me interesa.

Van implicadas aquí cuestiones de fondo, que no abordaré ahora; están ya esbozadas en mi libro, y han de ser expuestas con mayor amplitud en otros lugares. Diré sólo, por el momento, que no busco ninguna esencia ni sustancialidad durable en el hombre hispánico, ni en ningún tipo de hombre. "Si hay alguna definición de la naturaleza o "esencia" del hombre, esta definición puede ser entendida únicamente como funcional [subrayo yo], y no como sustancial" 1.

No pienso que la vida española sea islámica, sino que funciona (sean los que fueren en cada momento sus contenidos y sus valores) como una contextura vital, que no sería así sin las posibilidades antes presentes en las estructuras vitales de los cristianos, moros y judíos, es decir, de las formas en que sus vidas funcionaban en España, en la tierra de lo que ahora percibimos como la España de nuestra experiencia. No he psicologizado ni he esencializado la realidad hispánica. Cuando digo hispánico, me refiero a una manera única de existir, como comportamiento, como capacidad y tendencia funcional hacia ciertas realizaciones humanas (valiosas o desastradas), e incapacidad y resistencia a realizar otras. Dicha capacidad funcional, dada como estructura ( $\dot{i}$ en qué otro modo podría darse?), singulariza establemente a los pueblos como a los individuos. De no existir tal continuada singularidad, sería imposible establecer una relación inteligible entre lo hispánico de hoy y lo de ayer (vale lo mismo de lo francés, de lo alemán, o de lo que sea). En qué consista esa singularidad, y cómo quepa referirse a ella, es otro asunto.

La cuestión de cómo haya sido posible que una estructura se constituya a lo largo de los siglos es independiente, secundaria diría, respecto de la realidad de la estructura misma una vez fijada. Digo que la de Hispania se nos da como creencia-no pensamiento, en un complejo estructural en que cada uno de esos términos existe incómodamente junto al otro, e intenta desaferrarse de él, sin poderlo. La vida entonces se nos da como un "desvivirse"2. La creencia (cristiana, mesiánica, caudillista,

1 Ernst Cassirer, An essay on man, I944, pág. 68. El que juzgue útil hacer esta cita no significa que acepte yo la idea de Cassirer sobre en qué consista la realidad histórica del hombre.

2 Como digo en mi libro, los ejemplos que doy pudieran ser ésos u otros, muchos o pocos. La verdad de mi presentación no depende de que los "hechos" la prueben o la invaliden. Si tras largos años de convivencia con unas gentes, en toda posible forma, nos familiarizamos con sus fisonomías, sus acciones, con lo valioso o lo insoportable de cuanto hacen, y sentimos nuestras experiencias como algo único, porque ninguna de las otras gentes que frecuentamos son así, de nada nos serviría el intento de invalidar esa nuestra experiencia única con "hechos" que 
la que sea), si auténtica, nunca es problema para el creyente. "Cedat curiositas fidei", decía Tertuliano. EI yo del creyente es indisoluble del objeto de su creencia, no se distancia ni se retrae de él. El misterio de la Santísima Trinidad no tiene realidad entre los hombres sino como objeto de creencia, o de descreencia; en cambio el triángulo existe también fuera de quien lo piensa matemáticamente. Los hispano-cristianos pensaron poco $^{3}$. La relación de estructura entre la conciencia de la persona y la del mundo exterior a ella está dada en forma peculiar entre hispanos, sin que ello signifique que no haya en otras partes casos de fusión entre una realidad objetivada y la persona afectada por la experiencia de aquélla.

Tiene razón Spitzer en censurarme por no haber tenido presente el francés antiguo para construcciones del tipo de "les anocheció". Declaro que consulté los diccionarios para fr. ant. ajorner "amanecer', pero se me pasó decir que construcciones como "Et l'endemain quant lor ['les'] a ajorné" (Dict. de Tobler-Lommatzsch) no contienen referencia a una persona individual como en "amaneçió a Mio Çid en tierras de Mon Real". Al pronto pensé que si ambos sintagmas eran iguales gramaticalmente, no lo eran vitalmente, y no entré en más detalles. Ahora pienso, en verdad, que aunque sean iguales, sería un error en este caso equiparar la estructura de vida francesa a la española, porque nos encontremos con hechos similares en el lenguaje, o en cualquier otro campo. Construcciones tales como "il leur annuita" no persistieron en francés; qué duda cabe que en Francia hubo creencia, y la hay, aunque siempre se diese en una estructura diferente de la hispana, pues allí se puso en duda la realidad de las reliquias e incluso la existencia de Dios ya en el siglo xI, hubo un Jean de Meun en el siglo xiII, etc. Los hechos de una existencia no determinan lo que ésta sea, sino la estructura total de sentido en que se articulan y funcionan. Spitzer y yo partimos de concepciones distintas de la realidad humana, lo cual puede ser conveniente.

Como el enlace entre el sujeto y el objeto de una experiencia es fun-

probaran que tal y cual cosa de esas gentes únicas, ocurre o puede hallarse entre otras gentes. Lo real en el caso en cuestión no es este o el otro hecho, sino la estructura de vida, total y única, que hace de esas gentes algo único. La persona, individual o colectiva, no es un objeto de conocimiento como lo es, o puede serlo, un objeto físico o ideal; de éstos cabe decir que poseemos ideas adecuadas o erróneas, y probaremos lo uno o lo otro mediante una demostración, pues el peso atómico de un cuerpo es el que es y no otro. El objeto "hombre" es de otro modo; no cabe conocerlo exacta ni inexactamente, ni lleva a ninguna parte el reducirlo a un común denominador. De alguien se dice, por ejemplo, que carece de mucha inteligencia, y quienes lo piensan, lo eligen para presidente de la República sin ironía ni reserva mental algunas. El modo de acercarnos a esta realidad humana sería a través de la estructura vital del elector y del elegido, cosa que ahora no voy a intentar. La "medición" de la inteligencia(?) de una persona no permite aprehender su total realidad, su realidad humana.

${ }^{3}$ No creo posible encontrar entre hispano-cristianos medioevales textos como éste: "Pedro o Joan, quando sabe o magina en las cosas, sábelas una en pos de otra... Pedro, en tanto que magina en Sevilla, non puede maginar en Montpensler; o estando estudiando en el triángulo, non puede maginar nin estudiar en èl quadrángulo" (Rabi Arragel, glosas de la Biblia, ed. Alba, I, r26 b"). Por elemental que esto nos parezca ahora, ese estilo de "intelectual" objetivado tardó mucho en penetrar en el castellano de los cristianos. 
cional entre hispanos en forma distinta a como lo es entre franceses, la lengua española y la portuguesa van de "le anocheció" y "le amaneció" a "anochecí enfermo y amanecí sano". No trato de tal fenómeno como de un "hecho" lingüístico, sino como de un aspecto, entre cien otros, de la funcionalidad característica de una estructura histórico-vital. Al proceder así lo hago con el mismo rigor y la misma técnica que el más abstracto y exhaustivo lexicógrafo; no escribo mis ocurrencias, ni caigo en generalizaciones brillantes u opacas, ni me dejo arrastrar por ninguna pasión. ¿Qué pasión hay en parangonar a Santiago y a Mahoma, y en oponerlos polémicamente como los ingleses opusieron a su rey Arturo contra el francés Carlomagno? ¿Es pasión o "brillante ensayismo" poner a dos columnas las Partidas y el Alcorán, que copian, o a Ibn Hazm y a su seguidor Juan Ruiz? Una historia no se construye (es lo que estoy haciendo con rigor y cálculo) con ingenuidades sentimentales o eruditas. Evidentemente que me interesa no poco el tema (gané y perdí mucho en aquel juego); pero justamente por interesarme en tal grado he podido ver-sentir lo que un examen seudorracional nunca ha hallado. Cada género de meditación reclama su particular clima expresivo, si es que pretendemos que logren expresión ciertas realidades. Spitzer prefiere - admirable tarea - la gran cabalgada por los espacios sin confín del saber lingüístico-literario; yo me limito a contemplar y a labrar el huertecillo de mi propia vida, la única que en verdad menos malentiendo, - el problema de mis personales e intransferibles preocupaciones.

La funcional estructura de Hispania - su realidad - se da en "amanecí enfermo", y en mil otras manifestaciones que puede observar quien trate a hispanos del siglo xI en el santuario de Compostela, o a los del siglo xx en la Puerta del Sol de Madrid: ambos escenarios de vida me han sido igualmente accesibles y familiares. En ambos se funde la objetividad de la ley con el "me da la gana" del legislador o del legalizado: "allá van leyes do quieren reyes" (España en su historia, pág. 6I 7); la docta y lejana materia tratada por el sabio escritor se enreda en los accidentes empíricos del vivir de la persona, antes lo mismo que hoy (págs. 316, 672); el algo ennoblece al hijo en fijodalgo (págs. 7 I y 686), etc., etc. Lo objetivo del conocimiento y la experiencia vivida ahora por la persona se reciprocan como un dentro y un fuera que se alternan. El artista se injiere en su obra, y hace ver cómo es afectado por ella. La peculiar grandeza artística y heroica de ciertas obras y empresas hispánicas, y la constante anarquía frente a la ley, son anverso y reverso de una misma estructura vital.

Al no seguirme en mi intento de aclarar una cuestión de ontología humano-vital, es forzoso que se me malentienda, aunque es también posible que no me haya yo explicado con suficiente insistencia. Ya era significativo, sin embargo, que los españoles hicieran cuestión del modo de nombrar las ciudades americanas que fundaban o reedificaban (pág. 667 ), y que aquellos nombramientos fueran tratados como casos individuales. Bartolomé Colón llamó Santo Domingo la ciudad fundada por él "porque llegó allí un domingo, fiesta de Santo Domingo, y porque su padre se llamava Domingo" (pág. 667). Dos abstracciones independientes de la persona ("día domingo" y "fiesta de Santo Domingo") se 
triangulan en el vértice del sentimiento filial de un individuo, como el amanecer objetivo se injerta en las sensaciones del cuerpo de una persona: "Échase ome sano, e amanesçe frío" (Rimado de Palacio, 270). Se integran así en unidad realidades pertenecientes a mundos heterogéneos: abstracciones, fenómenos naturales, sentimientos y sensaciones. Para la voluntad personalizante del español no existen vallas, ni categorías separadoras, ni ideas claras y distintas.

Nada tiene esto que ver con llamar New los ingleses u holandeses a muchas ciudades americanas. Ya sabía que Newark, por donde paso a menudo, significó 'Nueva Arca de la Alianza'. Mas téngase en cuenta que la creencia religiosa de los puritanos (un nuevo mundo liberado de la opresión espiritual) y el $N e w$ que la expresa, son realidades genéricas, ideales y no personalizadas. Todos los puritanos se sentirían regenerados y renovados en las nuevas tierras. La idea de la regeneración religiosa flotaba sobre el vivir individual, o era un común denominador. Nada le pasaba singularmente a quien llamaba a un lugar New: expresaba una creencia y un sentimiento colectivos. Tan universal y abstracta es la noción implicada en $N e w$ que todos los pueblos de la tierra la usaron en su toponimia: ibero Ili Berri, celta Novio Dunum, eslavo Novo Gorod, latín Villa Nova; luego, Ville Neuve, Terranova, New Town, Neuburg, Nueva Granada, Nueva España, etc. Los modelos hispánicos influirían también en la toponimia de ingleses, holandeses y franceses en América: La Nouvelle Orléans. Todo ello es distinto de los casos personales que yo he presentado como expresión de la estructura de vida hispana : Osorno, en Chile, se llamó así porque la madre de García Hurtado de Mendoza, que la fundó, era condesa de Osorno; el granadino Jiménez de Quesada que fundó a Santa Fe de Bogotá, se acordaba de su Santa Fe granadina; los cordobeses llamaban Córdoba a las ciudades al pie de una sierra, etc. En suma, en el nombre de la ciudad de Santo Domingo no yace nada "santodomingable"; el New de New England responde a algo "newable", generalizable.

Insisto, por otra parte, en que incluso si resultaran falsos mis ejemplos linguísticos (aunque creo que casi todos ellos son pertinentes), mi libro no naufragaría. Si sabemos por propia y larga experiencia que alguien es un bailarín, no dejará de serlo aunque erremos en atribuirle estos o los otros bailes, si bien será preferible describir exactamente lo que baila: lo menciono sólo como ejemplo. Digo que la "gens hispana" posee una estructura funcional creyente-no pensante y que vive desviviéndose, desde la época en que nos es patente su intimidad, desde la Reconquista hasta hoy ${ }^{4}$. He sacado a relucir algunas palabras por ser cauces de vida significativa, sin ignorar que por esos cauces pueden discurrir aguas de varias procedencias. Las palabras son como esa puerta, reproducida en la pág. 444, que cumple su función "janual" con medios a la vez cristianos e islámicos. Tiene razón Spitzer en criticarme por no haber dicho que fr. ant. mesler, prov. mesclar y esp. mezclar 'calumniar' descansan sobre una base común románica. Ahora bien, el español posee

* Falta en España en su historia un capítulo sobre los Visigodos, que he de publicar pronto en forma de artículo de revista a fin de aclarar ciertas malas inteligencias. 
además dos nombres, mezclador y mesturero, sin paralelo en aquellas lenguas, y que para mí llevan inyectado el sentido del "wāšî" árabe, designador de un tipo social y literario, que el provenzal llamó lauzengier. En este vocablo también se halla presente el sentido árabe, según han hecho ver Menéndez Pidal, Nykl y otros buenos conocedores de la materia cuestionada. Siendo innegable la convivencia de las poesías cristiana y musulmana en el Libro de buen amor, no creo que quite ni añada al caso el que haya más o menos arabismo en mesturero. El bifrontismo y el arabesco "ontológico-vital" del Libro de buen amor, del yelmo de Mambrino, y de tanta otra cosa que no quiero citar aquí, nada padece porque en francés antiguo mesler significara también 'calumniar'. Reconozco, sin embargo, que no debí omitir ese detalle.

La doble faz de nuevas me parece todavía más clara. Bastaba ver el pasaje del Rabí Arragel citado en mi pág. 508. Respondiendo éste a la pregunta de por qué comienza el texto sagrado con el relato de la creación, dice: "El començamiento e ynovación del mundo, nescesario dezir era" (ed. Alba, I, 97). Añade que el mundo "ynovación de criador resçebido aver. . . Nos creer el mundo de nuevo fecho seer". ¿Cómo puede innovarse y ser hecho de nuevo lo creado ex nihilo? Pues admitiendo que, antes de cielos y tierra, Dios creó "una cosa de materia muy delgada inpalpable, salvo que es una tal massa aparejada para resçebir forma de qualquier cosa; la qual cosa que así dicho avemos, unos la llaman el ylle, e otros la llaman la primera materia; e esta materia es la que en principio crió" (pág. 97 b-q8 a). Dios, según Arragel, habría impuesto una nueva forma y un comienzo temporal a una materia situada entre Dios y el mundo que crea. El lenguaje nos lleva a serias complicaciones teológicas, que tocaré sólo para insistir una vez más sobre nuestro poco conocimiento de los enlaces vitales entre Oriente y Occidente en la Romanía. Aunque hasta los medio cultos han leído en los manuales que Averroes preocupó a los teólogos cristianos durante siglos ("Averrois, che il gran comento feo", Inferno, IV, I44), procedemos luego como si los textos latinizados, y accesibles por tanto, de sus obras, no hubieran estado presentes. Dice Averroes en su Doctrina decisiva y fundamento de la concordia entre la revelación y la ciencia que hay tres clases de seres existentes: "los seres temporáneos o innovados... el ser que no proviene de causa alguna [Dios]". Entre ambos extremos hay "un ser que ni está formado de cosa alguna preexistente, ni le precede el tiempo, pero que procede de alguna causa, es decir, de causa eficiente". Quienes piensan que ese ser intermedio se asemeja más al ser eterno que al ser producido, lo llamarán eterno; quienes juzgan que prevalece en él su semejanza con el ser producido, le llamarán producido ${ }^{5}$.

Comentó el anterior texto el judío Calo Calonymos, en su Liber de mundi creatione physicis rationibus probata, Venecia, I523. Llama "ens innovatum" al "generabile et corruptibile"; "ens antiquum" a "deus gloriosus". Hay además un "ens medium ... quod non fit ex materia sed ex agente"; tal es el mundo, el cual "recíbe la semejanza del ente inno-

${ }^{5}$ Me sirvo de la traducción de M. Alonso, en Teología de Averroes, 1947, pág. 176 . 
vado y del ente antiguo" ". Nos encontramos, pues, con el problema teológico y metafísico del origen y de la realidad del mundo creado según Averroes. Lo único que en ello interesa ahora es observar que los términos innovado y nuevo, aplicados a los entes y al mundo, responden a los sentidos de hadiz y hadaza en árabe, y no sólo a los latinos. Hadaza ofrece una complejidad y singularidad de sentidos, sólo posibles en una lengua semítica y en una concepción no occidental de la realidad: 'acontecer, ser nuevo, relatar algo, conversar, crear'. Según ya digo en España en su historia, pág. 254, "huduz, nombre del mismo tema que hadiz, es 'creación', pero una creación que incluye a su agente". No puedo entrar en excesivos detalles, pero he de insistir en la necesidad de tener presente un difícil problema, no soluble rápidamente. La creación es innovación, es algo así como una nueva forma o aspecto del creador; ya vimos antes cómo dice Calo Calonymos, traduciendo y explicando a Averroes, que el ente entre el creador y lo creado, entre lo antiguo y lo innovado, "accepit similitudinem entis irmovati et entis antiqui". No hay corte absoluto entre unos y otros entes. La dificultad de entender tal modo de pensar hizo que Averroes fuera, para sus traductores de la Edad Media, un racionalista que pensaba que el mundo era increado y eterno, cuando en verdad era un piadoso musulmán; según el Alcorán y según Averroes, "eterno" no significa necesariamente 'increado', esse a se, sino 'un existir dependiendo de otro'; pensar en un aeternum ab alio no implica aquí contradicción lógica, pues se trata de una creación sin comienzo, y no de un mundo eterno ${ }^{7}$.

En conexión con lo anterior hay que entender la "innovación", creación del mundo, en el texto citado del Rabí Arragel. La estructura vital y pensante del Oriente se entrecruza con el pensamiento y la expresión latino-románicos, y produce intrincados enredos, que estoy tratando de desenmarañar. Semejantes interferencias requerirían largas y minuciosas exposiciones, que en nada mermarían, sin embargo, la justeza y evidencia de lo que digo ahora y he escrito antes. El ens antiquum (Dios) enlaza con el ens innovatum (lo creado), como el contador de un cuento ( $\mathrm{ha}$ diz) se incluye o está presente en el cuento, llamado también hadiz, la cual palabra es forma derivada de hadaza 'ser nuevo, acontecer', etc. La estructura de ciertas formas del pensamiento europeo es análoga a la de ciertas formas de vida-expresión artística; un cuento es una "innovación", una nueva o novela, en enlace con su contador. En Las mil y una noches, en el Conde Lucanor de Don Juan Manuel, en el Decamerón de Boccaccio, o en Calila e Dimna, se incluyen los cuentos y quienes los cuentan. El cuento (hadiz, novela) es innovado-creado y crea a su vez la realidad que cuenta: el héroe del Poema del Cid es el "Campeador contado" ( 142 2, 152, 493, 178a), que Menéndez Pidal interpreta, con razón, 'famoso, ilustre's. Nuevas significa a veces 'creación, hazaña':

${ }^{6}$ Cita este texto M. Alonso, op. eit., pág. I77.

7 Véase M. Horten, Die Philosophie des Islam, i924, pág. 86.

s Para eliminar otro motivo de confusión recordaré que en las gestas francesas se alude al cantar a que los héroes han dado o pueden dar tema: "Dist l'uns a l'altre: j'ai öi un jougler; / Oiés con cante de Guillaume au court nez!"' (Le Moniage Guillaume, ap. R. Menéndez PIdal, Poesía juglaresca, pág. 327). En 
"Las nuevas que faze el Campeador" (1 343 ); "de grandes nuevas son los ynfantes" (2084); "ome sin grandes nuevas" (BEraeo, Milagros, 312). Nuestro asunto rebasa los límites de la lexicografía; ésta debe aceptar la realidad ontológico-vital de ciertas formas de la vida europea en las que se integran y están presentes (inada de influencias!) situaciones de vida oriento-occidentales. Si hay simbiosis arábigo-románica en la estructura literaria del Conde Lucanor y del Decamerón, es manifiesto que también la hay en los sentidos de nuevas, novas, nouvelle, en los que se injertan la tradición latino-románica y la oriental, lo mismo que se entrelazan el pensamiento cristiano y el islámico en Santo Tomás, en el averroismo europeo, en Raimundo Lulio -o en Algazel o Ibn Arabi, según ha demostrado Asín Palacios. Si cerramos los ojos a esta realidad, y no tenemos presentes las situaciones vitales como conjuntos dados en estructura, la filología se disolverá en irreales abstracciones y en anécdotas desmenuzadas, difíciles de recordar.

Repitamos que la estructura vital semítico-islámica no descansa sobre nociones de sustancia y esencia; es, por el contrario, transiente, fluyente, aspectual, un existir manante y emanante, reversible, interpenetrable e inconsistente. Por eso el novelar incluye lo extrapoético y lo poético, en el Cid, en el Quijote y en muchos otros casos, según he hecho ver suficientemente en otros lugares. Por eso no era entendible el Libro de buen amor del Arcipreste de Hita; queríamos forzarlo dentro de la lógica y la ontologia occidentales, dentro de la cual los seres poseen límites y no son reversibles e intercambiables; son, en una palabra, realidades esenciales y no flúidas. Hubo así que convertir el Cancionero del Arcipreste en una payasada anacrónica, sin enlace con nada en Europa - en una abstracción irreal. El que el libro del Arcipreste sea ahora lo que he hecho que resulte ser, no procede de ninguna figuración mía, sino de mi convivencia y mi ajuste con la estructura vital en que existe. Dice Max Horten (Philosophie des Islam, pág. 73) : "El ser es intercambiable con el uno, se adhiere sólo a los individuos. Queda así excluida la existencia de las ideas platónicas. Ser e individualidad son idénticos (Al-Farabí). El ser se junta, se añade a la esencialidad: es manifiesto a primera vista que ambos son totalmente distintos. Ni hay positiva esencialidad en el concepto del ser, ni tampoco está éste contenido en una esencialidad. Sólo en Dios coinciden ambos. Las cosas del mundo son, por tanto, contingentes: es decir, pueden ser o no ser"'.

Las lenguas son expresión de algo muy concreto y real: de la estruc-

La Chanson de Roland, el héroe esfuerza a los suyos para la batalla: "Or guart chascuns que granz colps i empleit, / Male cançun de nus dite ne seit!" (ror3-14). Giulio Bertoni comenta en su admirable edición (Florencia, 1936, pág. 48r ): "Para la preocupación de los héroes por lo que se narrará de ellos, v. Wilmotre, Romania, LIV, I 24"; y recuerda a Jeremías, Lamentationes, III, I4: "Factus sum in derisum omni populo meo, canticum eorum tota die". Añadiría yo a esto el latín "in fabulas ire". Mas por mucho que añadamos, el "Campeador contado" del Cid conservará su sentido propio; el canto, o el cuento, no existen como realidad trascendente a la persona, sino como algo integrado en la inmanencia del existir. El dar ocasión a cuentos o cantos es distinto de existir como contado o cantado; la misma estructura de vida que hizo posible el "Campeador contado" hizo también posible al Don Quijote de la Segunda Parte, inclusivo del Don Quijote contado por la Primera. 
tura y de la situación vital de unas gentes dadas en un tiempo dado. Una situación de vida románico-arábiga (peculiar por otra parte en cada país) se refleja en la forma literaria del Lucanor, Libro de buen amor, Decamerón, etc., así como en ciertos sentidos de nuevas, novela, en el averroísmo, en el mudejarismo arquitectónico de España, y en tantas otras manifestaciones de la realidad vital e histórica.

Respecto de los nombres literarios convertidos en nombres comunes, lo que tal vez delimite la peculiaridad hispana sea la comunización de los nombres literarios, y la ausencia de nombres como ohm 'unidad de resistencia eléctrica', voltio, amperio, etc., siempre importados. La estructura funcional de un pueblo consiste tanto en sus presencias y posibilidades como en sus ausencias e incapacidades. Huelga decir, por lo demás, que mi problema está en los antípodas de las discusiones sobre el Dauerfranzose, sostenidas hace años en Alemania. Pero esto ha de quedar para mejor ocasión.

He tomado las palabras mencionadas a veces en mi libro, como índice y muestras de una estructura vital, que he de seguir haciendo visible lo mejor que sepa, a fin de dotar de un sentido unívoco la palabra español, o hispano, hoy sin determinación rigurosa (lo mismo acontece a francés, alemán, etc.). Esos vocablos refieren a algo preciso, a una modalidadunidad de existir humanamente dentro de un límite histórico-temporal. La realidad del existir de un pueblo, que se impone a nuestra experiencia como irreductible singularidad, no consiste en lo que en ella haya de genérica abstracción, es decir, en lo que históricamente no sea: In interiore singulae vitae habitat veritas.

Escrito lo anterior, noto que Spitzer se refiere también a mi explicación de buena sombra. Sin querer sutilizar, ni obstinarme en puntos menudos, creo, sin embargo, que la expresión provenzal pourta marrido oumbro 'ser peligroso' suscita la imagen de la sombra que proyecta la persona (hay árboles cuya sombra daña a las plantas, etc.). Yo me refiero a la sombra incorporada, como aspecto, en la imagen o representación de la persona. En español (sobre todo en andaluz) se dice de alguien que es "un mala sombra, un mal ángel". En Menina e moça, de Bernardin Ribeiro, la "Menina" ve a una mujer que surge del bosque; se sorprende, pero "nam de medo, que a sua boa sombra m'o nam consentio" (ed. Michaëlis de Vasconcellos, II, I3). Aquí sombra es simplemente 'aspecto, expresión', motivadores de una buena impresión en quien contempla. Que el orientalismo en este caso sea no sólo arábigo, sino también hebraico, cabe muy bien en mi idea de la contextura cristianoislámico-judaica.

Spitzer aduce también en contra de mi idea de que Ojos del Guadiana es una metáfora árabe ( $a^{\varsigma}$ in 'ojo' y 'fuente') lo que G. Rohlfs dice en su artículo Griechischer Sprachgeist in Süditalien, publicado con posterioridad a la aparición de mi libro en los Sitzungsberichte der Bayerischen Akademie der Wissenschaften, I944-I 946, pág. 9. Al encontrarse con urbeghi en vascuence, que también significa 'ojo de agua', no han pensado en que el vascuence es en este caso como cualquier lengua románica, en cuanto a la época y procedencia de muchas de sus palabras. 
Todo el mundo sabe que Jaungoicoa 'Dios' en vasco vale 'Señor de lo alto', y es traducción del latín eclesiástico o del castellano. Luego hay en gascón ouelh d'aigo, en aragonés güello de ra fuande y en corso occhiu 'fuente', y ahí tenemos aniquilado el origen árabe. Rohlfs dice: "hay que presumir con cierta seguridad que el punto de partida para este metafórico modo de ver yace en el ibero". Pero esto porque en vasco hav urbeghi, sin que sepamos nada de su antigüedad. Pero aunque fuera antiguo, que no debe serlo, ¿cómo iba el ibero, suponiendo que el vocablo sea ibero, a inducir a los árabes asiáticos a llamar "ojo" a una fuente de agua? Spitzer y Rohlfs ignoran que también el hebreo hayin (igual al árabe $a^{\prime}$ in) significa 'ojo' y 'fuente'. Basta abrir el diccionarito de Leopold (Lexicon Hebraicum, 1910, pág. 278) para encontrarse con numerosas expresiones bíblicas formadas con hayin que significan 'duo fontes', 'fons hoedi', 'fons hortorum', 'fons habitationis', 'fons muro inclusus', 'fons vitulorum duorum', etc. ¿'Tendrá el lenguaje hebreo de la Biblia presencias ibéricas? En cuanto al corso occhiu, me limitaría a recordar que Córcega estuvo en poder de sarracenos desde mediados del siglo Ix a mediados del xI. Que en doscientos años tomara el lenguaje de aquellos isleños algo del habla árabe me parece más fácil que transportar el espíritu ibérico a la tierra de Judá. Mientras no encontremos "ojo de agua" significando 'fuente' en áreas separadas de la arabizada Iberia y de la cuenca mediterránea, propongo que sigamos aceptando mi idea del origen oriental de esta metáfora.

Aparte de todas estas minucias, el problema radical, lo repito, es si debemos seguir navegando por el mar sin confines de "lo humano", o si los historiadores debemos determinar previamente la modalidad del sujeto humano del cual predicamos la realidad histórica, de aquel y aquellos que están viviendo su historia en una estructura unívoca.

Princeton University.

Américo Gastro

\section{MISCELANEA GITANO-ESPAÑOLA}

\section{Manús 'hombre'}

Una de las palabras gitanas de más arraigo en el lenguaje popular español es gachó, con su femenino gachí. La variedad de significados que adquirió el masculino en su paso del caló al español ha sido la base de su gran difusión: La palabra, lo mismo que en otros dialectos gitanos, significó 'hombre', 'varón', 'no gitano', 'amante' (como en la frase es mi hombre), y sustituyó luego fácilmente a popularismos como tipo, tío, guapo (sustantivo), mozo, etc., sobre todo en expresiones ponderativas, hasta llegar a convertirse en una interjección similar al español ¡hombre! También el femenino gachí se empleó en alto grado, y se sigue empleando hoy, con el significado de 'mujer', 'prostituta', 'querida', 'hembra hermosa'. La pareja gachó-gachí constituye además para los filólogos el mejor ejemplo de conservación de la distinción entre las ter- 